\title{
Acute Effect of Mobile Phone on Cardiac Electrical Activity in Healthy Volunteers
}

\author{
T. Devasia1, A. Nandra', H. Kareem¹, M. K. Manu'2, A. S. Thakkar ${ }^{3}$ \\ ${ }^{1}$ Department of Cardiology, Kasturba Medical College \& Hospital, Manipal, India \\ ${ }^{2}$ Department of Pulmonary Medicine, Kasturba Medical College \& Hospital, Manipal, India \\ ${ }^{3}$ Department of Clinical Trials, Sahjanand Medical Technologies Pvt. Ltd., Surat, India \\ Email: tomdevasia@hotmail.com
}

Received 31 December 2013; revised 28 January 2014; accepted 27 February 2014

Copyright (C) 2014 by authors and Scientific Research Publishing Inc.

This work is licensed under the Creative Commons Attribution International License (CC BY). http://creativecommons.org/licenses/by/4.0/

(c) (†) Open Access

\begin{abstract}
Background: A large number of publications have appeared in medical and scientific literature which show the hazardous effects of the mobile phone due to its radiofrequencies on reproductive system, autonomic nervous and immune system as well as cardiovascular system. However, so far the biological effect of the radiofrequency emitted from the mobile phone was not clear. Aim: To assess the effect of mobile phone on electrical cardiac activity by analysing the heart rate, QT interval, corrected QT Interval and QT dispersions while the mobile phone is to the proximity of heart. Settings and Design: This prospective, non-randomized study was carried out at private tertiary care hospital, for the period of 24 months. Methods and Material: One hundred healthy human volunteers were recruited in the study based on inclusion and exclusion criteria. The heart rate and 12-lead electrocardiogram (ECG) were recorded in all the participants (supine position) in 3 situations: without mobile phone, mobile phone switched on (not ringing), and mobile phone ringing. We performed statistical analysis of variance $(p<0.05)$ to compare the ECG variables in all three situations. Results: There was no statistically significant difference observed in heart rate and ECG variables (QT interval, corrected QT interval, QT dispersion) in three groups $(p>0.05)$. Conclusions: We conclude that the mobile phone positioned to the proximity of the heart has no effect on the heart rate or cardiac electrical activity.
\end{abstract}

\section{Keywords}

Mobile Phone; Heart Rate; ECG Variables

\section{Introduction}

The use of mobile phone has been increasing dramatically in the past decade. World Health Organization has es-

How to cite this paper: Devasia, T., Nandra, A., Kareem, H., Manu, M.K. and Thakkar, A.S. (2014) Acute Effect of Mobile Phone on Cardiac Electrical Activity in Healthy Volunteers. International Journal of Clinical Medicine, 5, 167-170.

http://dx.doi.org/10.4236/ijcm.2014.55029 
timated that currently there are 4.6 billion subscriptions globally [1]. The current digital global system for mobile communication (GSM) operates through radiofrequencies (RF) ranges from $900 \mathrm{MHz}$ to $1800 \mathrm{MHz}$ [2].

Various studies have revealed that the exposure to RF leads to adverse effects on reproductive system, cardiovascular system, autonomic nervous system as well as immune system [3]-[6]. Both human epidemiological studies and animal based (experimental) studies are demonstrating the carcinogenic potential of RF generated electromagnetic field (EMF) [7] [8].

Though the mobile phone companies are reassuring the safety of their devices, animal studies as well as epidemiological studies show the harmful effects of mobile phone on biological systems. So, the public interest for the hazardous effects of mobile phone on human health has risen.

Research on the effect of mobile phone on cardiovascular system has yielded controversial results. So, we have carried out this study to determine the effects of mobile phone on electrical cardiac activity by analyzing the heart rate, QT interval, and corrected QT Interval $\left(\mathrm{QT}_{\mathrm{C}}\right)$ and $\mathrm{QT}$ dispersions $\left(\mathrm{QT}_{\mathrm{d}}\right)$ while the mobile phone is to the proximity of heart of healthy human.

\section{Materials and Methods}

This was prospective, non-randomized and single center study carried out from January 2010 to January 2012 in Electrocardiogram (ECG) lab of private tertiary care hospital of Karnataka. The study protocol was approved by the institutional ethics committee of the hospital prior to the commencement of the study. The clinical study was performed in accordance with International Conference on Harmonisation-Good Clinical Practice (ICH-GCP) guideline. Informed consent was obtained from all the participants recruited in the study.

One hundred healthy human volunteers were included in the study as per following inclusion and exclusion criteria.

Inclusion Criteria:

- Normal cardiovascular examination;

- Normal baseline ECG and echocardiogram—-to confirm the normal structural and functional cardiovascular status.

Exclusion Criteria:

- If the patient is diagnosed to have right bundle branch block (RBBB) and left bundle branch block (LBBB) during ECG examination;

- If the patient is diagnosed with structural heart abnormalities, ischemic or rheumatic heart disease, left ventricular dysfunction during ECG or echocardiography;

- If the patient having hypertension, diabetes, thyroid disorder or electrolyte imbalance.

\subsection{Description of Study Procedure}

The participants were asked not to drink tea, coffee or cola containing beverages or alcohol before 24-hour of ECG recording to minimize the effect of these factors on ECG variables or heart rate. The participants were requested not to use mobile phone before 24-hour of the recording of the ECG.

We used Nokia 2600 MP (2G, GSM 900/1800, Nokia Corporation, Helsinki, Finland) to study the effect of RF on heart rate and ECG variables. The mobile phone was set into silent mode (non-vibrating mode) so that the patients were not able to understand whether it is ringing, on or off. The phone was placed in the left pocket of the shirt (anterior wall of the chest).

ECG was used for 12-lead ECG recording of the participants (supine position). The 12-lead ECG (baseline) was recorded using ECG machine (Philips Pagewriter TC 20) when mobile was not nearby the participant. $2^{\text {nd }}$ ECG was taken with the mobile phone on his left pocket-anterior chest wall and switched on (silent mode, not vibrating), but not ringing. $3^{\text {rd }}$ ECG was taken with the mobile phone switched on, and ringing (silent mode, but not vibrating), on the same spot on the left anterior chest wall.

We have used software (Philips DXL ECG Algorithm) for analysis of various ECG variables. The variables are defined as follow: QT interval (beginning of QRS complex to the end of T wave) was measured in all the derivations. This measured QT intervals were corrected by Bazett's formula and defined as QTc [9]. QTd was defined as the difference between longest QT interval and shortest QT interval. 


\subsection{Statistics}

All data were analysed using the Statistical Package for Social Sciences (SPSS; Chicago, IL, USA) program, version 15 with the assistance of statistics department at Manipal University. To compare the ECG variables in all three situations (no mobile phone nearby, mobile phone switched on but not ringing, mobile phone ringing), statistical analysis of variance (ANOVA) with $\mathrm{p}<0.05$ was performed.

\section{Results}

Total 100 (mean age $30.5 \pm 5.2$ years) healthy human volunteers were included in the study. There were 60 male patients. After examination of 12-lead ECG of all the participants in 3 different conditions, the following results are obtained, shown in Table 1. There is no statistically significance difference ( $p>0.05)$ observed among the groups for various variables like heart rate, $\mathrm{QT}$ interval, $\mathrm{QT}_{\mathrm{C}}$ interval and $\mathrm{QT}_{\mathrm{d}}$.

\section{Discussion}

A large number of experimental studies on healthy human volunteers have been carried out after the published literature which demonstrated the impact of mobile phone on cardiac pacemakers [10]. The public interest towards the harmful health effects of the mobile phone increased when Ozguner et al. demonstrated increase in oxidative stress in rat myocardium upon RF exposure [7].

Our study showed statistically insignificant difference $(p=0.938)$ in heart rate. The result of our study was comparable with the result of study carried out by Atlasz et al. which also conclude that there was no significant difference observed between RF (emitted by mobile phone) and sham experimental groups even though the exposure were for the period of $10 \mathrm{~min}$ [11]. Tahvanainen et al. has also reported that mobile phone exposure does not acutely change heart rate [12]. However, Braune et al. carried out the study on human volunteer and reported that in response to elevated blood pressure (5 - $10 \mathrm{~mm} \mathrm{Hg}$ ) due to $900 \mathrm{MHz}$ RF exposure, auto-regulatory mechanism become activated. The consequence of activation of this mechanism leads to decrease in heart rate. However, in this study the volunteer were exposed to RF for the period of 35 min [13].

The change in $\mathrm{QT}_{\mathrm{C}}$ and QT dispersion in ECG reflect abnormal ventricular repolarization. However, our study showed insignificant difference in $\mathrm{QT}_{\mathrm{C}}$ and QT dispersion in all three situations (no mobile phone, phone not ringing and phone ringing). The result is similar to that of the study conducted by Tamer et al. [14].

It is necessary to find out whether the radiofrequencies emitted from mobile phones (on a long term basis) produces or contributes to any other ill effects like cardiovascular disease as there are some studies carried out in animals demonstrated that long term exposure of radiofrequencies ( $2 \mathrm{hr}$ or $3 \mathrm{hr} / \mathrm{day}$ for 8 weeks) lead to decrease in heart rate as well as prolonged $\mathrm{QT}_{\mathrm{C}}$ interval in albino rats [15]. However, such studies have not been carried out in human.

We also need to analyze if chronic mobile phone use produces slow but consistent changes in repolarization and depolarization variables of the heart along with its nature (induced changes are reversible or irreversible).

\section{Conclusion}

Our prospective study of 100 healthy volunteers conclude that cellular phones have no significant effect on the measured electrical cardiac activity when the cellular phone is placed in close proximity to the heart-anterior

Table 1. Comparison of heart rate and ECG variables of all the participants in three situations.

\begin{tabular}{ccccc}
\hline Parameter & Baseline (Mean \pm SD) & Phone Not Ringing (Mean \pm SD) & Phone Ringing (Mean \pm SD) & p Value \\
\hline Heart Rate $(\mathrm{bpm})^{1}$ & $74.58 \pm 15.21$ & $74.08 \pm 15.07$ & $74.83 \pm 15.01$ & 0.938 \\
$\mathrm{QT}$ Interval (ms) & $381.24 \pm 37.31$ & $382.96 \pm 36.64$ & $384.00 \pm 37.00$ & 0.868 \\
$\mathrm{QT}^{3}$ Interval (ms) & $406.49 \pm 22.57$ & $407.42 \pm 21.43$ & $405.77 \pm 42.94$ & 0.930 \\
$\mathrm{QT}_{\mathrm{d}}^{4}(\mathrm{~ms})$ & $46.88 \pm 22.67$ & $47.54 \pm 22.67$ & $47.52 \pm 23.91$ & 0.974 \\
\hline
\end{tabular}

${ }^{1}$ bpm: beats per minute; ${ }^{2} \mathrm{~ms}$ : milliseconds; ${ }^{3} \mathrm{QT}_{\mathrm{C}}$ : Corrected QT; ${ }^{4} \mathrm{QT}$ : QT dispersion. 
chest wall in normal subjects.

\section{References}

[1] World Health Organization (2013) Electromagnetic Fields and Public Health: Mobile Phones. http://www.who.int/mediacentre/factsheets/fs193/en/

[2] Makker, K., Varghese, A., Desai, N.R., Mouradi, R. and Agarwal, A. (2009) Cell Phones: Modern Man's Nemesis? Reproductive Biomedicine Online, 18, 148-157. http://dx.doi.org/10.1016/S1472-6483(10)60437-3

[3] Wilen, J., Hoernsten, R., Sandström, M., Bjerle, P., Wiklund, U., Stensson, O., Lyskov, E. and Mild, K.H. (2004) Electromagnetic Field Exposure and Health among RF Plastic Sealer Operators. Bioelectromagnetics, 25, 5-15. http://dx.doi.org/10.1002/bem.10154

[4] Szmigielski, S., Bortkiewicz, A., Gadzicka, E., Zmyslony, M. and Kubacki, R. (1998) Alteration of Diurnal Rhythms of Blood Pressure and Heart Rate to Workers Exposed to Radiofrequency Electromagnetic Fields. Blood Pressure Monitoring, 3, 323.

[5] Liu, X., Yan, S., Ding, X., Zhang, N., Lu, H. and Tang, J. (2003) Evaluation of Radiation Damage to the Sperm DNA of Radar Operators. National Journal of Andrology, 9, 494.

[6] Croft, R.J., Chandler, J.S., Burgess, A.P., Barry, R.J., Williams, J.D. and Clarke, A.R. (2002) Acute Mobile Phone Operation Affects Neural Function in Humans. Clinical Neurophysiology, 113, 1623-1632. http://dx.doi.org/10.1016/S1388-2457(02)00215-8

[7] Ozguner, F., Altinbas, A., Ozaydin, M., Dogan, A., Vural, H., Kisioglu, A.N., Cesur, G. and Yildirim, N.G. (2005) Mobile Phone-Induced Myocardial Oxidative Stress: Protection by a Novel Antioxidant Agent Caffeic Acid Phenethyl Ester. Toxicology and Industrial Health, 21, 223-230. http://dx.doi.org/10.1191/0748233705th2280a

[8] Schüz, J. and Ahlbom, A. (2008) Exposure to Electromagnetic Fields and the Risk of Childhood Leukaemia: A Review. Radiation Protection Dosimetry, 132, 202-211.

[9] Hannan, P.J. and Crow, R.S. (1997) Concerning the Units for the QT Interval Corrected by Bazett's Formula. Circulation, 96, 3799.

[10] Barbaro, V., Bartolini, P., Donato, A., Militello, C., Altamura, G., Ammirati, F. and Santini, M. (1995) Do European GSM Mobile Cellular Phones Pose a Potential Risk to Pacemaker Patients? Pacing and Clinical Electrophysiology, 18, 1218-1224. http://dx.doi.org/10.1191/0748233705th2280a

[11] Atlasz, T., Kellényi, L., Kovács, P., Babai, N., Thuróczy, G., Hejjel, L. and Hernádi, I. (2006) The Application of Surface Plethysmography for Heart Rate Variability Analysis after GSM Radiofrequency Exposure. Journal of Biochemical and Biophysical Methods, 69, 233-236. http://dx.doi.org/10.1016/j.jbbm.2006.03.017

[12] Tahvanainen, K., Nino, J., Halonen, P., Kuusela, T., Laitinen, T., Laensimies, E., Hartikainen, J., Hietanen, M. and Lindholm, H. (2004) Cellular Phone Use Does Not Acutely Affect Blood Pressure or Heart Rate of Humans. Bioelectromagnetics, 25, 73-83. http://dx.doi.org/10.1002/bem.10165

[13] Huber, R., Graf, T., Cote, K.A., Wittmann, L., Gallmann, E., Matter, D., Schuderer, J., Kuster, N., Borbély, A.A. and Achermann, P. (2000) Exposure to Pulsed High-Frequency Electromagnetic Field during Waking Affects Human Sleep EEG. Neuroreport, 11, 3321-3325. http://dx.doi.org/10.1097/00001756-200010200-00012

[14] Tamer, A., Gündüz, H. and Ozyildirim, S. (2009) The Cardiac Effects of a Mobile Phone Positioned Closest to the Heart. Anadolu Kardiyoloji Dergisi, 9, 380-384.

[15] Mohamed, F.A., Ahmed, A.A., El-Kafoury, B.M. and Lasheen, N.N. (2011) Study of the Cardiovascular Effects of Exposure to Electromagnetic Field. Life Science Journal, 8, 260-274. 